\title{
El CASTIGO APLICADO AL TyRANNUS ARGIMUNDO SEgÚN EL Chronicon de JuAn de Bíclaro
}

\author{
José Ángel Castillo Lozano y José Antonio Molina Gómez
}

(Universidad de Murcia)

Resumen: En este estudio analizamos la figura del tirano Argimundo y los castigos que sufre tras fracasar en su rebelión contra Recaredo (586-601) según lo que nos relata la crónica del obispo de Gerona, Juan de Bíclaro. Para este estudio, nos serviremos del paralelo formal que documenta el obispo Julián de Toledo en su Historia Wambae Regis acerca de la serie de castigos que sufre Paulo, el rebelde que se alza contra el reinado de Wamba (672-680). Con ello, pretendemos arrojar luz acerca de la creación literaria de la figura del tyrannus en la tradición visigoda, los castigos que este recibe y su especial lugar en la concepción del poder en el imaginario colectivo de este pueblo.

Palabras clave: castigo, tyrannus, rebeldes, concepción del poder, Argimundo, Juan de Bíclaro.

ABSTRACT: The aim of this study is to examine the tyrannical leading figure of Argimundo and the punishments he endures after failing in his armed upraising against Reccared's government (586-601) according to John of Bíclaro, bishop of Gerona. We will make use of the conventional parallel documented by bishop Julian of Toledo in his Historia Wambae Regis about the punishments imposed on Paul, the rebel who attempted to take up arms against Wamba's reign (672-680). Our main purpose is to shed light on the literary creation of the tyrannus figure within the Visigoth tradition, and its special place in the conception of power in this people's collective imaginary.

Keywords: punishment, tyrannus, insurgents, conception of power, Argimundo, Juan of Bíclaro. 


\section{INTRODUCCIÓN}

T a naturaleza de la realeza visigoda, sus orígenes, su evolución, sus Latributos y sus símbolos de poder han sido ya objeto de atención por una gran parte de la investigación moderna con notables resultados. ${ }^{1} \mathrm{Sin}$ embargo, no da la impresión que el antagonista al rey legítimo, el tyrannus, haya gozado del mismo interés. ${ }^{2}$ El término tirano se reserva según Orlandis ${ }^{3}$ para pessimos atque improbos reges que someten a sus pueblos a una cruel y abusiva dominación en contraposición al rey, término que se utiliza para señalar a aquellos que gobiernan con justicia y rectamente. Por ello, los reyes y los usurpadores tendrán una serie de características propias, definidas y hasta cierto punto ajustadas a una tipología reconocible. Objetivo de nuestro trabajo es analizar las características del segundo grupo, es decir, la desafortunada ralea de tiranos y usurpadores condenados por el juicio de la historiografía visigoda, así como los castigos a los que les somete el primer grupo, el de los reyes legítimamente constituidos, con el objeto de asentar firmemente sus amenazadas cualidades regias y asentar de igual forma su propio pensamiento teológico y político.

Las usurpaciones fueron un mal endémico en toda la historia visigoda fruto en parte de las debilidades estructurales de la monarquía, como su carácter

1. Algunos de los trabajos más importantes y que nos han sido de gran utilidad su previa lectura y análisis para la confección de este estudio son, ordenados cronológicamente, los siguientes: M. TORRES LÓPEZ: «El estado visigodo», AHDE 3, 1926, pp. 307-475; C. SÁNCHEZ AlbORNOZ: «La ordinatio principis en la España goda y postvisigoda», CHE 35, 1962, pp. 5-36; J. ORLANDIS (1962): El poder real y la sucesión al trono en la monarquía visigoda. Estudios visigodos III. Roma-Madrid; A. BARbERo AgUILAR: «El pensamiento político visigodo y las primeras unciones regias en la Europa medieval», Hispania 30, 1970 pp. 245-336; G. Alföldy: Die monarchische Repräsentacion mi römischen Kaiserreiche. Darmstadt, 1980; P. D. KING: Derecho y sociedad en el reino visigodo. Madrid, 1981; algunas alusiones en lo que respecta a la figura del monarca ideal en M. BLOCH: Les rois thamauturges. París, 1983; hemos utilizado como guía la siguiente obra que si bien, se enmarca en un periodo cronológico distinto, nos ha proporcionado ideas muy interesantes para abordar nuestro trabajo: F. PAschoud y J. SzidAT (eds.): Usurpationen in der Spätantike.

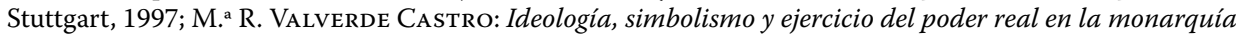
visigoda: un proceso de cambio. Salamanca, 2000; F. Коцв: Herrscherideologie in der Spätantike. Berlín, 2001; M. A. Rodríguez de la PeÑa: Los reyes sabios. Cultura y poder en la Antigüedad Tardía y la Alta Edad Media. Madrid, 2008 y E. H. Kantorowicz: Los dos cuerpos del rey. Un estudio de teología política medieval, Madrid, edición 2012.

2. A excepción de algunos trabajos clásicos como los siguientes: J. OrLANDis: «En torno a la noción visigoda de tiranía», $A H D E, 29,1959$, pp. 5-43; J. BALOGH: «Rex a recte regendo», Speculum vol. 3, n. 4, 1928, pp. 580-582; J. Orlandis, «Algunas observaciones en torno a la tiranía de San Hermenegildo», Temis 2, 1957, pp. 67-75; J. MALdonado Ramos: «Algunos puntos precedentes y puntos oscuros de la rebelión de San Ermenegildo» en M. Bejarano, M. Montoro y D. Sandoval (dirs.): Los visigodos y su mundo. Jornadas internacionales. Ateneo de Madrid. Noviembre de 1990, Madrid, 1998, pp. 61-69; A. IGLESIAS Ferreiro: Historia de la traición. La traición regia en León y Castilla. Santiago de Compostela, 1971 y A. GUIANCE: «Rex perditions. La caracterización de la tiranía en la España visigoda», Cuadernos de Historia de España, 77, 2001-2002, pp. 29-40. El penúltimo libro mencionado, cuyo autoría pertenece a Iglesias Ferreiro, corresponde a la publicación de la tesis doctoral de este investigador y dedica unos primeros capítulos introductorios a la idea de tiranía en el mundo visigodo habida cuenta de que será esta la que perdure en la Plena y Baja Edad Media española. Recientemente, nosotros también analizamos con cierta profundidad la figura de Paulo en el siguiente estudio: J. A. CASTiLlo LozAno: «La figura del tyrannus, del rebelde, en la tradición visigoda a través de las obras de Julián de Toledo», Herakleion, 7, 2014, pp. 85-101.

3. J. OrLandis, «En torno», pp. 8 y 31. 
electivo dentro de la nobleza y la ausencia, pese a intentos excepcionales, de dinastías estables, que llevó adjunto esas luchas por el poder, ${ }^{4}$ ese mal crónico, denominado con la célebre expresión «enfermedad goda» o morbus gotorum. ${ }^{5}$

En este sentido el testimonio que nos lega Juan de Bíclaro sobre los castigos a los que se somete a este Argimundo, sigue un interesante paralelo formal si se compara con las noticias que da Julián de Toledo para Paulo en su Historia Wambae Regis, obra más conocida y estudiada que la anterior. ${ }^{6}$ De la comparación con ambas se deduce la existencia de un modelo normalizado en el procedimiento a seguir con los tiranos derrotados en lo legal y una concepción en lo ideológico del rebelde paralela e indisociable del monarca legítimo al amparo del modelo bíblico. Por ello hemos decidido tratar la figura de aquel que se levanta contra el rey por lo que representa. Es decir, se trata del reverso simbólico del monarca legítimo, ambas son figuras idealizadas, tipificadas en la tradición historiográfica y en la cosmovisión legal de la época; al mismo tiempo se trata de figuras antagónicas pero complementarias entre sí, y es que cuanto más legitimidad histórica y moral reciba el rey de los cronistas e historiadores de la época, menos legitimidad se le otorgaba al tirano. Al imaginario del «tirano» pertenecían no solo eventuales nobles díscolos, sino incluso a aquellos indígenas y extranjeros, adversarios del rex, se les veía como potenciales usurpadores destructores de leyes. ${ }^{7} \mathrm{El}$ hecho de oponerse a un rey puesto por Dios para defender la justicia, la sabiduría y el derecho (como el rey ideal Salomón, guerrero, sabio, poeta, juez comerciante y arquitecto, v. I Reyes 10,9), según el esquema bíblico de la época, suponía equiparar la rebelión a un acto sacrílego.

El usurpador complementaría en el terreno de la ideología política al rey porque sus vicios, su perfidia, su abuso del poder, su hybris -que dirían los griegos antiguos- no hacen sino brillar la figura del monarca, según un esquema teológico favorable a la sacralidad del poder y que hunde sus raíces en Eusebio de Cesarea e incluso en la tradición cristiana anterior y su concepción del monarca cristiano. ${ }^{8}$ En consecuencia, el estudio del denominado «tirano» nos ayuda a entender el arquetipo de monarca ideal en tanto que el rey no podría ser tal si no tuviera su contrario, que no hace sino consolidar y fortalecer los atributos asignados por la pluma del obispo de Gerona y del obispo de Toledo a

4. I. Velázquez Soriano: «Wamba y Paulo: Dos personalidades enfrentadas y una rebelión», Espacio, Tiempo y Forma, Serie II, Historia Antigua, t. II, p. 216 y H. J. Diesner: «Bandas de criminales, bandidos y usurpadores en la España visigoda», Hispania Antiqua. Revista de Historia Antigua, vol. III, p. 129.

5. Chron. Fredeg. IV, 82.

6. Una bibliografía amplia y actualizada respecto a la obra del obispo de Toledo y el propio gobierno de Wamba la encontramos en: J. Martínez Pizarro: The Story of Wamba. Julian of Toled's Historia Wambae Regis, Washington. 2005, pp. 241-256.

7. H. J. Diesner: «Bandas de criminales, bandidos y usurpadores», p. 133.

8. J. A. Straub: Vom Herrscherideal in der Spätantike, Stuttgart, 1964, pp. 113-129; del mismo autor, Regeneratio Imperii. Aufsätze über Roms Kaisertum und Reich im Spiegel der heidnischen und christlichen Publizistik, tomo II, «Des christlichen Kaisers 'secunda maiestas'. Tertullian und Konstantinische Wende» Darmstadt, 1986, pp. 63-74 (=Zeitscrift für Krichengeschichte 90, H.2/3, 1979, 147-157). 
los reyes Recaredo y Wamba en clara oposición a los asignados a Argimundo y, finalmente, a Paulo. Esto es algo lógico puesto que los historiadores visigodos siempre estuvieron de parte de la legalidad creando un discurso legitimista que busca la estabilidad de política, como sugiere acertadamente Hillgarth. ${ }^{9}$ El poder temporal es querido por Dios para probar y aleccionar al hombre y ya desde la interpretación patrística de ambos testamentos se ha pedido a los fieles no la sumisión, pero sí la colaboración leal y sincera con el gobierno en términos aceptables para los creyentes (v. por ejemplo Jeremías 29, 4-7; Romanos 13, 1-7; Mateo 17, 27).

En lo que ya se refiere a Argimundo, para García Moreno ${ }^{10}$ sería $d u x$ provinciae que posiblemente también ostentara el cargo de cubicularius antes de su levantamiento contra Recaredo. No sabemos con exactitud de que provincia era $d u x$. Collins supone que sería el $d u x$ de la Cartaginense. ${ }^{11}$ Una reciente monografía apunta la posibilidad de que este personaje fuese de origen suevo a través de un estudio estudio antroponímico que divide su nombre en dos radicales: Arge/Argí- y -mundus llegando a la conclusión de un posible origen suevo de este personaje. ${ }^{12}$ De Paulo poco sabemos de su vida anterior a su levantamiento contra Wambae. Díaz y Díaz ${ }^{13}$ afirma que Paulo es el mismo comes notariorum que acudió a los Concilios VIII (del 653) y IX (del 655) entre los viri illustres officii palatini. En términos parecidos se expresa García Moreno ${ }^{14}$ que en principio separa a ese Paulo que acude a los Concilios VIII y IX con el que se rebela aunque indica, de igual modo, que no se sabe nada de la vida de este rebelde con anterioridad a su levantamiento armado contra el poder monárquico. En la investigación moderna ha habido un amplio debate en los círculos académicos debido a que se ha generado una amplia controversia al ver algunos investigadores que se trataría de un romano o un bizantino, tal y como su nombre sugiere. ${ }^{15}$ El hecho de que hubiera podido ser un romano-bizantino, explicaría para algunos su ceremonia de coronación, habida cuenta de que los visigodos no habrían contado con ella en este momento. ${ }^{16}$ Sin embargo, no hemos de dudar que estas coronas visigodas poseían una marcada influencia del mundo bizantino. ${ }^{17}$ Con todo, asumimos la idea de que este hecho no tiene tanto que ver con la coronación de un no

9. J. N. Hillgarth: «Historiography in Visigothic Spain», en La storiografia altomedievale: settimane di studio del centro italiano di studi sull'alto medioevo, XVII, 10-16 aprile 1969. Spoleto, 1970, pp. 299-302.

10. L. García Moreno: Prosopografía del reino visigodo de Toledo, Salamanca, 1974, pp. 34-35.

11. R. Collins: La España visigoda, Barcelona, 2005, p. 78.

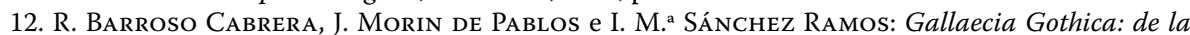
conspiración del Dux Argimundus (589/590 d. C.) a la integración en el reino visigodo de Toledo, Madrid, 2015 , p. 36.

13. P. R. DíAz y DíAz: «Julián de Toledo: Historia del rey Wamba (Traducción y notas)», Florentia Iliberritana 1, 1990, p. 92.

14. L. García Moreno, Prosopografía, pp. 65-68.

15. E. A. Thompson: Los godos en España, Madrid, ed. 2007, p. 267.

16. J. Arce Martínez: «El conjunto votivo de Guarrazar: función y significado», en A. PereA (ed.): El tesoro visigodo de Guarrazar, Toledo, 2001, p. 353.

17. M. a R. VAlverde Castro, Ideología, simbolismo y ejercicio, pp. 96-97. 
godo, como con un acto sacrílego al ponerse la corona de san Félix donada a Dios por Recaredo. ${ }^{18}$

Por este motivo, este artículo pretende arrojar luz sobre la teoría política y la concepción de poder real en una época bisagra entre la Edad Antigua y la Edad Media, a través del estudio de los crímenes ${ }^{19}$ y castigos aplicados a esta figura tan denostada por la historiografía tradicional y por el gremio de los historiadores.

\section{Los Atributos Del Rebelde Argimundo}

La crónica de Juan de Bíclaro, a pesar de pertenecer al aparentemente género «neutral» de las crónicas hispanas de época visigoda, ${ }^{20}$ muestra evidentes juicios de valor; de ahí que investigadores como Julián Campos, ${ }^{21}$ Galán Sánchez ${ }^{22}$ o Hillgarth ${ }^{23}$ asuman que la crónica de este obispo de Gerona sea, dependiendo del acontecimiento, de parcialidad variable. De esta forma, será aparentemente más neutral cuando habla de hechos alejados al reino visigodo de Toledo como, por ejemplo, cuando nos narra distintos sucesos acontecidos en el Imperio bizantino. Sin embargo, generaría opiniones más interesadas cuando menciona hechos importantes acontecidos en el reino de Toledo como cuando habla de usurpaciones, o cuando nos relata la conversión al catolicismo de Recaredo. Esta conversión será uno de los hechos a los que el obispo de Gerona más importancia dará; y así se colige por el grado de exactitud cronológica que le otorga el autor excepcionalmente, pues es el único hecho en toda la crónica que presenta año y mes en el que sucedió ${ }^{24} \mathrm{Di}$ chas opiniones aparecen parcialmente veladas por los mecanismos y recursos propios del género cronístico.

Juan de Bíclaro realiza un discurso cargado de fuerza y subjetividad cuando nos relata la usurpación y la condena del rebelde Argimundo que había inten-

18. J. A. Molina Gómez: «Las coronas de donación regia del tesoro de Guarrazar: la religiosidad en la monarquía visigoda y el uso de modelos bizantinos», Antigüedad y Cristianismo xxı, 2004, p. 470.

19. Este tema del abuso del poder ha sido tratado recientemente, aunque no en época visigoda, en la siguiente monografía: P. GILly (ed.): La pathologie du pouvoir: vices, crimes et délits des gouvernants. Antiquité, Moyen Âge, époque moderne, Leiden/Boston, 2016.

20. Las características generales de este género historiográfico, así como el análisis de las principales crónicas visigodas hispanas, lo encontramos en P. J. GALÁN SÁnCHEZ: El género historiográfico de la chronica. Las crónicas hispanas de época visigoda, Cáceres, 1994. Para la de Juan de Bíclaro: pp. 81-172.

21. «Sin emitir juicios sobre sus relatos, fuera de dos acontecimientos del reinado de Recaredo, el triunfo del duque Claudio sobre los francos y la celebración del Concilio III de Toledo, en los que introduce una interpretación religiosa y providencialista», J. CAmpos: Juan de Bíclaro, obispo de Gerona. Su vida y su obra. Introducción, texto crítico y comentario, Madrid, 1960, pp. 54-55.

22. «Sin embargo, a medida que se profundiza más en la lectura de su obra hay que concluir que su elogiada imparcialidad es solo relativa», P. J. GALÁN SÁNCHEZ, El género historiográfico, p. 97.

23. «Juan de Bíclaro no es tan imparcial como se ha dicho», J. N. Hillgarth: «La conversión de los visigodos. Notas críticas», Analecta Sacra Tarraconensis, 34, 1961, p. 24.

24. P. J. Galán SÁnCHez, El género historiográfico, p. 94 
tado arrebatar el trono a Recaredo. Creemos acertada la tesis de Thompson ${ }^{25}$ al pensar que esta sublevación solo buscaba el poder y no habría tenido connotaciones tantas religiosas arrianas ${ }^{26}$ como sí habría sido el caso de dos anteriores sediciones durante el reinado de Recaredo si bien, actualmente, se tiende a pensar que son luchas entre distintos poderes secundarios y el central. El párrafo que le dedica a este personaje es muy significativo para entender el pensamiento político de este autor en particular y el del mundo visigodo en general, por lo que nos hemos visto en la obligación de traerlo aquí:

Reccaredo ergo orthodoxo quieta pace regnante domesticae insidae praetenduntur. Nam quidam ex cubiculo eius, etiam provinciae dux nomine Argimundus adversus Reccaredum regem tyrannidem assumere cupiens, ita tu, si posset, eum regno privaret et vita. Sed nefandi eius consilii detecta machinatione comprehensus et in vinculis ferreis redactus habita discuccione socii eius impiam machinationem confesii condigna sunt ultione interfecti, ipse autem Argimundus, qui regnum assumere cupiebat, primum verberibus interrogatus, deinde turpiter decalvatus, post haec dextra amputata exemplum omnibus in Toletana urbe asino sedens pompizando dedit et docuit famulus dominis esse superbos.

J. Bícl., Chron., a. 590, 3

Al leer este fragmento, podemos observar cómo a Argimundo se le aplica toda una serie de tópicos y atributos que conforman el estereotipo de la figura del tyrannus dentro de la tradición literaria visigoda, y que coinciden con los que Julián de Toledo otorga a Ilderico y a Paulo en su Historia Wambae Regis. Frente al monarca legítimo, la Historia Wambae Regis presenta con los términos tyrannus (tyrannidis), seditiosus (seditio), coniurator (coniurato) y rebellis (rebellionis) a los usurpadores o rebeldes. Dichos vocablos aparecen en esta obra literaria 42 veces ${ }^{27}$ lo que viene a mostrarnos el importante papel que este personaje ajeno al poder legítimo ocupa en la concepción real y en el entendimiento de esta obra, es el enfrentamiento entre la legalidad y la ilegalidad de ambos personajes. ${ }^{28}$ Este comportamiento lo experimenta de igual manera este fragmento ya que nos aparece también una serie de términos que muestra el lugar especial asignado a estos personajes. Así, Juan de Bíclaro nos mencionará los términos tyrannidem, nefandi eius e impiam machinationem.

De igual manera, vemos como los términos nefandi e impiam pueden llegar a albergar cierta connotación religiosa ${ }^{29} \mathrm{y}$ es que este $d u x$ se levanta

25. E. A. Thompson, Los godos, p. 127

26. Como al parecer si piensan investigadores tan reputados como R. Collins y J. Arce. R. Collins, $L a$ España, p. 78 y J. ArCe Martínez: Esperando a los árabes. Los visigodos en Hispania (507-711), Madrid, 2011. pp. 151-152.

27. G. García Herrero: «Julián de Toledo y la realeza visigoda», Antigüedad y Cristianismo viI, 1991, p. 217.

28. R. Frighetto: «Legitimidade e poder da realeza hispano-visigoda, segundo a História Wambae de Juliano de Toledo (segunda metade do século viI)», Espaço Plural, 30, p. 105.

29. P. J. GaLÁN SÁnCHEZ, El género historiográfico, p. 169. 
contra el rey legítimo al que intentará asesinar y arrebatar el reino pero, al mismo tiempo, se levantará contra Dios. Esto se explica dentro del imaginario colectivo visigodo en una suerte de crimen de alta traición que a su vez deriva de una herencia del mundo romano pues la noción de este crimen, maiestas, no tenía precedentes en la sociedad goda. ${ }^{30}$

El crimen hacia Dios radica en ir en contra de los juramentos que todo súbdito ha de realizar a su nuevo monarca a ojos de Dios. Estos juramentos actuarían como una ordalía anticipada ${ }^{31}$ como una auténtica institución cuyos orígenes provienen del mundo indoeuropeo ${ }^{32}$ y que a su vez actuaría como «mecanismo de construcción de poder en un contexto de inestabilidad política y debilidad estructural de la aristocracia y el estado» ${ }^{33}$ al dotar la figura del rey de un elemento sacro. El incumplimiento de este juramento acarreaba toda una serie de penas tanto espirituales como terrenales que el derecho visigodo regulaba ${ }^{34}$ y que iban dirigidas tanto a laicos como a eclesiásticos. ${ }^{35}$ El objetivo era claro: proteger el reino, al rey y a la familia real contra los usurpadores. ${ }^{36}$

Este juramento también partía del rey hacia sus súbditos siendo un claro ejemplo de derecho público. ${ }^{37}$ Con este juramento, el monarca se comprometía a respetar sus privilegios y a gobernar con justicia tal y como se incide en el canon Lxxv del IV Concilio de Toledo. ${ }^{38}$ Sin embargo, en este mismo canon se prevé que en el caso de que el monarca no cumpla lo acordado, sus súbditos no pueden castigarle, ya que ese deber únicamente responde a Dios, por lo que en esta concepción de la categoría de Dios como juicio histórico el súbdito jamás debe tomar la iniciativa de actuar contra la ley, incluso cuando el monarca tome decisiones que atenten contra el juramento que él debe tomar con y para su pueblo. ${ }^{39}$ Por ello, aquel rey que se comporte como un tirano, será apartado por Jesucristo y condenado como anatema y, posteriormente, será condenado por Dios ${ }^{40}$ como se expresa en el canon LXXv del IV Concilio de Toledo al que hicimos con referencia anteriormente. De la misma manera, encontramos en este mismo canon el concepto de fidelidad que se le debía al monarca visigodo y las consecuencias

30. P. D. KIng, Derecho y sociedad, pp. 60-61.

31. J. Alvarado Planos: «Ordalías y derecho en la España visigoda», III Congreso de Estudios Medievales. De la Antigüedad al Medievo. Siglos IV-VIII. Madrid, 1993, p. 487.

32. E. BenVEniste,: Vocabulario de las instituciones indoeuropeas, Madrid, ed. 1983, pp. 334-341.

33. S. S. ORLOWSKI: «Fideles regis en el reino visigodo de Toledo: aproximaciones para su estudio desde las prácticas reciprocitarias», Miscelánea Medieval Murciana, xxxıv, 2010, p. 85.

34. M. ${ }^{\text {a }}$ R. VAlverde CAStro, Ideología, simbolismo y ejercicio, p. 218

35. A. Iglesias Ferreiro: Historia de la traición. La traición regia en León y Castilla, Santiago de Compostela, 1971, pp. 45-46.

36. C. Petit: «De negotiis causarum (II)», AHDE, 56, 1986, pp. 7-20.

37. M. TORRes López: «El estado», pp. 439-441.

38. J. Vives Gatell, T. Marín Martínez y G. Martínez Díez: Concilios visigóticos e hispanoromanos, Madrid, 1963, p. 267.

39. M. ${ }^{a}$ R. VAlverde Castro, Ideología, simbolismo y ejercicio, p. 217.

40. A. Iglesias Ferreiro, Historia de la traición, p. 62. 
que tenía romper este juramento hacia la figura del rey que englobaba a él mismo, al reino y a sus gentes. Es más, en el canon x del XVI Concilio de Toledo $^{41}$ se llegan a extender los castigos de la ignomiosa acción de levantarse contra el monarca a los hijos de aquel que empezara la sedición.

Esto da sobrada cuenta del discurso que se articula contra estos rebeldes y los castigos que acompañarán a sus impías acciones, ya que no corresponde a ellos solucionar terrenalmente la afrenta sustituyendo a un mal rey por un regicida. En el caso concreto que nos ocupa, Recaredo y Wamba son concebidos como monarcas justos en la tradición historiográfica visigoda, y por esa razón la concepción del tirano en estos reinados es si cabe más clara pues, los prototipos de reyes ideales imitan claramente los modelos veterotestamentarios ${ }^{42}$ encaminados a sancionar la legitimidad del monarca y a señalar como enemigos de Dios y de la religión a quienes osaran quebrar su fidelidad.

\section{El esquema PeCAdo/CAstigo. UnA CONCEPCión TEOlÓgiCA DEL POder}

De acuerdo con el pensamiento histórico de Juan de Bíclaro, tan marcado por el providencialismo y el Juicio de Dios como categoría histórica, la rebelión de Argimundo únicamente podía finalizar de una forma. El destino final, una vez descubierta su conjura, fue un castigo ejemplar en Toledo al $d u x$ que se alzó contra el feliciter gobierno de Recaredo. Así nos lo hace llegar el Biclarense:

deinde turpiter decalvatus, post haec dextra amputata exemplum omnibus in Toletana urbe asino sedens pompizando dedit et docuit famulos dominis non esse superbos.

J. Bícl., Chron., a. 590, 3

Al leer el pasaje que dedica Julián de Toledo al castigo de Paulo, no podemos sino darnos cuenta de la existencia de un cierto paralelismo y es que no debemos olvidar que Julián de Toledo utilizó el Chronicon del Biclarense para la elaboración de algunos de sus pasajes de la Historia Wambae Regis. ${ }^{43}$ Salvando las distancias, pues son distintos hechos los que narran y porque la obra de Juan de Bíclaro es una crónica, mientras que la de Julián de Toledo se ha llegado a proponer que no se trate de una simple historia, sino de una vita o exemplum heredera directa de los panegíricos bajoimperiales y a su vez testadora de las vitae y panegíricos medievales. El pasaje de la Historia Wambae Regis que relacionamos con el de arriba es el siguiente:

41. J. Vives Gatell, T. Marín Martínez y G. Martínez Díez, Concilios, pp. 509-512.

42. G. García Herrero, «Julián de Toledo», pp. 241-246.

43. S. Teillet: Des goths à la nation gothique. Les origines de l'idée de nation en Occident du Ve au VII ${ }^{e}$ siècle, París, 1984, p. 445. 
Etenim quarto fere ab urbe regia miliario Paulus princeps tyrannidis uel ceteri incentores seditionum eius, decaluatis capitibus, abrasis barbis pedibusque nudatis, subsqualentibus ueste uel habitu induti, camelorum uehiculis imponontur. Rex ipse perditionis praeibat in capite, omni confusionis ignominia dignus et picea ex coreis laurea coronatus. Sequebatur deinde hunc regem suum longa deductione ordo suorum dispositus ministrorum, eisdem omnes quibus relatum est uehiculis insedentes eisdemque inlusionibus acti, hinc inde adstantibus populis, urbem intrantes. Nec enim ista sine dispensatione iusti iudicii Dei eisdem accessisse credendum est, scilicet tu alta ac sublimia confusionis eorum fastigia uehicolorum edoceret sessio prae omnibus subiecta, et qui ultra humanum morem astu mentus excelsa petierant excelsiores luerent conscensionis suae iniuriam. Sint ergo haec insequuturis reposita saeculis, probis ad uotum, improbis ad exemplum, fidelibus ad gaudium, infidis ad tormentum, tu utraque pars in contuitu quodam sese lectionis huius inspiciens, et quae rectis smitis graditur, prolapsionis casus effugiat, et quae iam cecidit, in horum se hic semper proscriptionibus recognoscat.

Julián de Toledo, Historia Wambae Regis, 30

La diferencia de ambos fragmentos estriba en que la rebelión de Paulo fue más lejos que la de Argimundo y le dio tiempo a proclamarse monarca (sin unción) y a autocoronarse de una forma pecaminosa desde el momento en que utilizó una corona consagrada destinada únicamente a fines litúrgico, en una época que posiblemente la corte visigoda no practicara ceremonias de coronación, sino de unción. ${ }^{44}$ Por ello, el castigo de Paulo también irá asociado a unos elementos simbólicos de poder relacionados con la indumentaria real como la conocida corona de donación regia de san Félix que puso en su «desvariada cabeza» a lo que une «el sacrilegio a la usurpación». ${ }^{45}$ En cualquier caso, lo que se busca es parodiar esa coronación realizada al margen del poder legal por lo que el simbolismo negativo de estos atributos es evidente, ${ }^{46}$ como la cinta de cuero negra con la que es coronado (coronatus), lo que potencia la infamante forma de exhibir al reo. ${ }^{47}$

Sin embargo, son más las similitudes las que les unen. Para empezar, ambos castigos se ejecutan en la capital del reino, Toledo, lo que nos hace pensar como existe una cierta voluntad de exhibir al rebelde en las calles de la capital para afianzar la figura del rey frente a otros potenciales usurpadores, y es que no debemos olvidar que si bien la figura del usurpador nace de unos tópicos y lugares comunes dentro de la literatura visigoda, no es menos cierto que la figura del rey en estos últimos años del reino de Toledo está totalmente determinada por una serie de fuerzas periféricas. Esto nos desvela desajustes estructurales dentro de la monarquía visigoda. En esta situación, nos encontramos fricciones y eventuales conflictos entre una monarquía que

44. C. L. SÁnChez-Albornoz, «La ordinatio principis», pp. 5-36.

45. Julián, Hist, 26.

46. J. MARTÍNEZ PIZARro, The Story of Wamba, p. 220.

47. Ibid., p. 220, n. 133. 
buscaba asumir mayores esferas de poder y una nobleza (civil y religiosa) que monopolizaba los altos cargos del organigrama estatal y que basaba su poder en una red de lazos clientelares. ${ }^{48}$ Con toda probabilidad, Paulo y Argimundo reunirían en torno a sus personas el descontento de todos los sectores en conflicto en los lugares concretos donde la rebelión triunfa, lo que acentúa su carácter regional sin menoscabo de las repercusiones de mayor grado que pudieran desencadenarse. Esto vendría a significar que para la realización de estas sublevaciones tendrían que contar con cierta base social de apoyo, siguiendo el acertado estudio de Diesner sobre las bandas de criminales, bandidos y usurpadores en la Hispania visigoda, de la nobleza laica y religiosa sola no podría haber estallado esta sublevación llevada a cabo por Argimundo y Paulo, ya que «los usurpadores necesitaban amigos en todas las capas de la población».49 Esto nos hace ver que para que estalle este movimiento hostil debe haber un apoyo de una masa social suficientemente fuerte para al menos iniciar el movimiento. Por lo aquí explicado, creemos que la rebelión de estos dos duces se ha de entender en el contexto en la que se produce: la lucha de contrapoderes del estado que aspiran a tener mayor autonomía, la lucha entre el poder central y los poderes secundarios que han ido germinando desde finales del reinado de Recaredo, ${ }^{50}$ ya que tanto la nobleza como la monarquía basaban su poder en las mismas fuentes de riqueza y ambas buscaban el control de estas, así como la propia debilidad del reino de Toledo. Todo esto se puede entender en un marco de creciente desarticulación de los poderes estatales y el crecimiento de las influencias personales de carácter provincial, regional y a escala más local aún como ciudades y territorios.

Considerando de nuevo los castigos, vemos como ambos son decalvados, pena que parece que solo se documenta en dos ocasiones en la historiografía visigoda: la rebelión de Argimundo y el intento de usurpación de Paulo. ${ }^{51}$ En los casos de usurpación al trono, la decalvatio es una forma de infamia pública ${ }^{52}$ al suponer una degradación abierta que impide a aquel que la sufre poder ejercer la dignidad regia al representar el cabello ${ }^{53}$ un signo tradicional de distinción y de nobleza en las estirpes germánicas. ${ }^{54} \mathrm{~A}$ día de hoy, los especialistas en el tema aún no se ponen de acuerdo ${ }^{55}$ acerca de lo que sería exactamente el

48. K. F. Stroheker: Garmanentum und Spätantike, Zúrich, 1965, pp. 236-239.

49. H. J. Diesner, «Bandas», p. 140.

50. M. ${ }^{a}$ R. VAlverde CASTro, Ideología, simbolismo y ejercicio, p. 255.

51. J. Crouch: «The Judicial Punishment of Decalvatio in Visigothic Spain: a Proposed Solution based on Isidore of Sevilla and the Lex Visigothorum», The Mediterranean Review, 3/1, 2010, p. 61.

52. S. M. Castellanos García: Los Godos y la Cruz. Recaredo y la unidad de Spania, Madrid, 2007, pp. 613-614.

53. Al respecto, recomendamos el siguiente estudio: J. M. Wallace-Hadrill: The Long Haired Kings, Londres, 1962.

54. J. Arce Martínez, Esperando, p. 155; pero sobre todo P. E. Schramm: «Brustbilder von Königen auf Siegelringen der Völkerwanderungszeit», en la obra del mismo autor Herrschaftszeichen und Staatssymbolik, Schriften der MGA, vol. I, Stuttgart, 1954, pp. 213-237.

55. Al respecto, hay un interesante debate en J. CrOuCH, «The Judicial Punishment of Decalvatio», pp. 62 y $76-78$. 
castigo de la decalvatio, pues algunos piensan que consiste en la amputación entera o parcial del cuero cabelludo, mientras que otros opinan que se trataría del simple hecho de rapar el pelo. De esta manera, Thompson ${ }^{56}$ llega a decir que no sabe si la víctima era escalpada o si se le afeitaba la cabeza. Por otro lado, autores como Zambrana Moral ${ }^{57}$ afirman que en la decalvación también se llevaban cruentas aplicaciones como desollar la frente del condenado. Sin embargo, la propia decalvación que sufriría Wamba, por motivos menos graves, sugiere no tanto un carácter cruel como simbólico. ${ }^{58}$

En cualquier caso, parece claro que a pesar de que ambos autores hablen de la decalvatio, lo hacen de distinta forma por lo que nos podría estar diciendo que, en el reino visigodo de Toledo, habría distintos grados de decalvación. Juan de Bíclaro nos habla de que Argimundo es turpiter decalvatus, mientras que Paulo es, en palabras de Julián de Toledo, decaltionis tantum. De todas formas, el acto legislativo que aplica la pena es claro y su valor simbólico fuerte.

Posteriormente, a Argimundo se le amputa la mano derecha. Dicha pena proviene del derecho romano/bizantino ${ }^{59} \mathrm{e}$ imposibilita visiblemente y de por vida para la acción política, la participación en la vida civil.

El último episodio de esta serie de castigos que se le aplica a Argimundo por levantarse contra Recaredo consiste en el desfile burlesco del usurpador por las calles de Toledo en un asno, como también lo sufrió tiempo después Paulo al alzarse contra Wamba. Dicho castigo supone un escarnio público, una humillación, ${ }^{60}$ para degradar a aquel que osaba alzarse contra el poder legítimo encarnado en la figura sacra del monarca visigodo como se ha apuntado anteriormente, y es además una parodia sarcástica de la tradición bíblica que hacía desfilar al rey legítimo sobre un asno como símbolo de poder ${ }^{61}$

Además, sabemos que surge toda una regulación del perdón, un poder que pertenecerá al rey. Esto lo enseñan las leyes y los cánones conciliares como el canon x del XVI Concilio de Toledo que permite a Egica la posibilidad de perdonar a aquellos que hubiesen atentado contra la autoridad regia en el pasado o que lo fueran a hacer en el presente o como el LV 2, 1, 8 en el que se estipulan ciertos supuestos de perdón para que lo aplique Chindasvinto.

56. E. A. Thompson, Los godos, p. 423, n. 48.

57. P. Zambrana Moral: «Rasgos generales de la evolución histórica de la tipología de penas corporales», Revista de Estudios Históricos-Jurídicos, XXVII, 2005, p. 210.

58. J. A. Molina Gómez: «Las dos coronas de Paulo: elementos simbólicos de vestimenta y poder durante el reinado de Wamba», en Carmen Alfaro Giner, Jónatan Ortiz García y María Antón Peset (ed.): Tiarae, Diadems and headdresses in the Ancient Mediterranean Cultures. Symbolism and Technology, Valencia, 2014, pp. 263-271.

59. R. S. López: «Byzantine Law in the Seventh Century and its Reception by the Germans and the Arabs», Byzantion XVI, 1942-1943, pp. 454 y L. BreHIER: Les institutions de l' Empire Byzantin, París, 1970 , p. 197.

60. M. McCormicк: Eternal Victory, Triumphal Rulership in Late Antiquity, Byzantium and the Early Medieval West. Cambridge, 1986, pp. 303-304.

61. P. RiEDE: «Esel», en Biblelexicon, Deutsche Bibelgesellschaft, https://www.bibelwissenschaft.de/ stichwort/17820/. (Consultado: 20/12/2015) 
Además, esta potestad reserva a la gracia una posición en el derecho oficial del reino visigodo que nos hace ver la naturaleza viva y dinámica de este derecho. ${ }^{62}$

Finalmente, al estudiar y analizar ambos fragmentos podemos llegar a la tesis de que el providencialismo y el Juicio de Dios como categoría histórica articula toda la acción. De esta forma, ambos autores no dudan en señalar que estos hechos se han producido por intervención divina al sancionar un crimen, un sacrilegio de estas personas frente al rey legítimo que actuaría como una especie de vicario de Dios en la Tierra, por mandato celestial es un corregente divino, ${ }^{63}$ se trata del concepto del princeps religiosus frente al tyrannus, al príncipe de la perfidia. De la misma manera, no deja de apreciarse un tono sarcástico de estos autores al describirnos los finales y los castigos aplicados a los participantes de estas sediciones.

\section{REFLEXiones FinAles}

A lo largo del presente estudio hemos ido analizando la figura del tyrannus Argimundo siguiendo el paralelo formal del Paulo de la Historia Wambae Regis y hemos visto como las fuentes reflejan la mentalidad visigoda y de su concepción del poder en estas fuentes primarias (la crónica de Juan de Bíclaro y la obra de Julián de Toledo), por lo que creemos que estamos preparados para reunir todas esas ideas y conformar estas conclusiones.

En primer lugar, observamos la creación de una figura tipificada de tirano, es decir, se traza un personaje ambicioso, malicioso, cobarde y que ataca ya no solo la autoridad real sino al propio Dios. La figura del tirano se forma a base de estereotipos que se han ido generando en la tradición literaria visigoda. Son el reverso simbólico de los reyes ungidos y al servicio de Dios, corregentes con Cristo, cuyos atributos son totalmente opuestos a estos personajes, a los que hasta cierto punto necesitan a su vez para poder afianzar sus virtudes. Se contraponen las figuras del monarca piadoso frente al príncipe de la perfidia, asimilado en el lenguaje de la predicación con el demonio y sus obras.

Esta perfidia que hemos comentado a su vez conecta con la concepción religiosa del esquema pecado/castigo. El pecado o la falta viene dada al incumplir un juramento de fidelidad y de obediencia al rey que cada súbdito debía firmar al principio de cada reinado. Dicho juramento actuaría como una ordalía anticipada produciendo que el usurpador al incumplirlo atente

62. C. Petit: «Crimen y castigo en el reino visigodo de Toledo», en M. Bejarano, M. Montoro y D. Sandoval (dirs.): Los visigodos y su mundo. Jornadas internacionales. Ateneo de Madrid. Noviembre de 1990, Madrid, 1997, p. 228.

63. P. B. Schramm: «Mitherrschaft im himmel ein Topos des Herrscherkults in christlicher Einkleidung», en P. WirTh, (ed.): Polykronicon Festschrift für Franz Dölger, Heidelberg, 1966, pp. 480-485; P. C. Díaz Martínez y M. ${ }^{a}$ R. VAlverde Castro: «The Theoretical strenght and pratical Weakness of the Visigothic Monarchy of Toledo», en F. Theuws y J. L. Nelson (eds.): Rituals of Power from Late Antiquity to Early Middle Ages, Brill, Leiden, Boston, Colonia, 2000, pp. 59-94. 
gravemente contra los mandatos bíblicos y va en contra del mismo Dios al intentar apoderarse del reino contra su voluntad. A estos hechos, Paulo, además, se adueña de unas coronas cuyo único destinatario era Dios. Al tratarse de coronas de donación, al crimen terrenal y religioso también añade el sacrilegio.

Todas estas afrentas contra el orden que rige el mundo deben tener un castigo habida cuenta de que la teoría político-religiosa que legitima el poder del rey en el organigrama estatal tiene rasgos teocráticos, como también encontramos el pensamiento de Juan de Bíclaro y de Julián de Toledo. Por añadidura, la traición suponía un grave escarnio contra la estabilidad interna del reino y de la paz. Por tanto, resulta lógico pensar que a todos estos crímenes y sacrilegios realizados por estos usurpadores les acompañe una serie de castigos, siguiendo el modelo pecado-castigo, como los que les acontece a Argimundo y a Paulo una vez sus revueltas son desbaratadas y ellos capturados. Además, al comparar ambos sucesos vemos unas semejanzas reveladoras que nos llevan a pensar que Julián de Toledo o bien se sirvió como modelo del castigo que recibe Argimundo según el Biclarense para crear su propio relato de la pena de Paulo, o bien ambos participan, más allá de deudas y paralelos formales, de una concepción compartida en cuanto al usurpador y al monarca dentro de una interpretación teológica de la historia.

Las penas que se les aplican parecen destinadas en exclusiva a aquellos que atentan contra la dignidad regia y parece que las leyes que las regulan provienen del derecho romano/bizantino. Los castigos a los que hacemos mención son principalmente la amputación de la mano derecha y la decalvatio, único castigo que según Arce ${ }^{64}$ parece no venir del mundo romano sino del propio mundo godo y germánico, aunque ciertos especialistas como Patlagean hablan de que probablemente dicha pena ya fuera una práctica en uso dentro del sistema penal romano, ya que en la $E k \log \hat{e}^{65}$ parece que se muestra un castigo equivalente a la decalvatio.

Los castigos contaban con una evidente carga simbólica, como ya dijimos con anterioridad. Por añadidura, la decalvación entra plenamente en el imaginario colectivo godo, al ser los largos cabellos el símbolo tradicional de poder en una monarquía sin coronas como era la visigoda. La última parte del castigo consistía en que estos condenados recorrieran las calles de Toledo portando todas sus miserias a modo de burla hacia los rebeldes y también a modo de advertencia ante futuras sediciones. Todos iban encaminados a terminar con las guerras intestinas que desangraban al reino toledano.

Aparte de las penas, encontramos que el derecho visigodo también regulaba el perdón de los reos. Este poder iba destinado a la figura del monarca el cual podía ejercerlo para salvar al condenado de la muerte. En el caso de Paulo,

64. J. Arce Martínez, Esperando, p. 157.

65. E. Patlagean: «Byzance et le blason pénal du corps», en Du châtiment dans la cité. Supplices corporels et peine de mort dans le monde antique, Roma, 1982, p. 406. 
Julián de Toledo relata como Wamba, imbuido por la piedad cristiana, decide perdonar la vida a aquel que se ha levantado contra su gobierno. Sin embargo, el perdón no era total pues al condenado se le solía embargar los bienes, se le podía llegar a cegar, como es el caso de Paulo, ${ }^{66}$ lo que llevaba aparejada una clara exclusión social del orden establecido dentro de la monarquía católica.

Finalmente, hemos de subrayar la idea de que, a estos personajes, por muy distintas que fueran sus motivaciones, se les aplicaba una serie de castigos estereotipados siguiendo el esquema pecado/castigo tan presente en la sociedad visigoda, donde el providencialismo ocupaba un papel de primordial importancia para determinar la acción humana y donde el Juicio de Dios se había convertido en una categoría histórica. Por ello, podemos concluir mencionando que estos castigos son aplicados a estos personajes impíos que han osado ir contra el rey y, por ello, han incurrido en una falta más grave, ir contra Dios, ya que el rey y la monarquía tienen carácter sacro como sagrada es ya la sociedad desde finales del Imperio romano. En el pensamiento teocrático visigodo la rebelión no tiene justificación alguna, siempre es Dios quien castiga, de ahí las duras sanciones de las que Argimundo y Paulo son víctimas.

\section{FuENTES (EDICIONES UTILIZADAS)}

\section{JuAn De Bíclaro: Chronicon}

Álvarez Rubiano, P.: «La crónica de Juan Biclarense. Versión castellana y notas para su estudio», Analecta Sacra Tarraconensia, 16, 1970, pp. 7-44.

CAmpos, J.: Juan de Bíclaro, obispo de Gerona. Su vida y su obra. Introducción, texto crítico y comentario, Madrid, 1960.

Fernández Jiménez, F. M.: «El Chronicon de Juan de Bíclaro. La crónica del rey Leovigildo y del III Concilio de Toledo. Estudio y traducción», Toledana, 16, 2007, pp. 29-66.

\section{Julián DE TOLedo: Historia Wambae Regis}

DíAz y DíAz, P. R.: «Julián de Toledo: Historia del rey Wamba (Traducción y notas)», Florentia Iliberritana 1, 1990, pp. 89-114.

Levinson, W.: «Historia Wambae Regis», en J. Hillgarth (ed.): Sancti Iuliani Toletanae Sedis Episcopi Opera Pars I, Corpus Christianorum, Series Latina CXV, Turhout, 1974, pp. 213-255.

Martínez Pizarro, J.: The Story of Wamba. Julian of Toled's Historia Wambae Regis, Washington, 2005.

66. Jul., Iudicium, 7. 
BibLIOGRAFÍA

Alföldy, G.: Die monarchische Repräsentacion mi römischen Kaiserreiche. Darmstadt, 1980.

Alvarado Planos, J.: «Ordalías y derecho en la España visigoda», III Congreso de Estudios Medievales. De la Antigüedad al Medievo. Siglos IV-VIII. Madrid, 1993, pp. 437-540.

Arce Martínez, J.: Esperando a los árabes. Los visigodos en Hispania (507711), Madrid, 2011.

- «El conjunto votivo de Guarrazar: función y significado», en A. PerEa (ed.): El tesoro visigodo de Guarrazar, Toledo, 2001, pp. 349-355.

BAlOGH, J.. «Rex a recte regendo», Speculum vol. 3, n. 4, 1928, pp. 580-582.

BArbero Aguilar, A.: «El pensamiento político visigodo y las primeras unciones regias en la Europa medieval», Hispania 30, 1970 pp. 245-336.

Barroso Cabrera, R., Morin de Pablos, J. y Sánchez Ramos, I. M.a: Gallaecia Gothica: de la conspiración del Dux Argimundus (589/590 d. C.) a la integración en el reino visigodo de Toledo, Madrid, 2015.

Benveniste, J.: Vocabulario de las instituciones indoeuropeas, Madrid, ed. 1983.

BLOCH, M.: Les rois thamauturges. París, 1983.

Brehier, L.: Les institutions de l' Empire Byzantin, París, 1970.

Castellanos García, S. M.: Los Godos y la Cruz. Recaredo y la unidad de Spania, Madrid, 2007.

Castillo Lozano, J. A.: «La figura del tyrannus, del rebelde, en la tradición visigoda a través de las obras de Julián de Toledo», Herakleion, 7, 2014, pp. 85-101.

Crouch, J.: «The Judicial Punishment of Decalvatio in Visigothic Spain: a Proposed Solution based on Isidore of Sevilla and the Lex Visigothorum», The Mediterranean Review, 3/1, 2010, pp. 59-81.

Díaz Martínez, P. C. y Valverde Castro, M. ${ }^{a}$ R.: «The Theoretical strenght and pratical Weakness of the Visigothic Monarchy of Toledo», en F. THEUws y J. L. Nelson (eds.): Rituals of Power from Late Antiquity to Early Middle Ages, Brill, Leiden, Boston, Colonia, 2000, pp. 59-94.

Diesner, H. J.: «Bandas de criminales, bandidos y usurpadores en la España visigoda», Hispania Antiqua. Revista de Historia Antigua, vol. III, 1978, pp. 129-142.

Frighetto, R.: «Legitimidade e poder da realeza hispano-visigoda, segundo a História Wambae de Juliano de Toledo (segunda metade do século viI)», Espaço Plural, 30, pp. 89-116.

Galán SÁnchez, P. J.: El género historiográfico de la chronica. Las crónicas hispanas de época visigoda, Cáceres, 1994.

García Herrero, G.: «Julián de Toledo y la realeza visigoda», Antigüedad y Cristianismo vil, 1991, pp. 201-255 
García Moreno, L.: Prosopografía del reino visigodo de Toledo, Salamanca, 1974.

Gilly, P. (ed.): La pathologie du pouvoir: vices, crimes et délits des gouvernants. Antiquité, Moyen Âge, époque moderne, Leiden/Boston, 2016.

GuiAnCE, A.: «Rex perditions. La caracterización de la tiranía en la España visigoda», Cuadernos de Historia de España, 77, 2001-2002, pp. 29-40.

Hillgarth, J. N.: «La conversión de los visigodos. Notas críticas», Analecta Sacra Tarraconensis, 34, 1961, pp. 21-46.

- «Historiography in Visigothic Spain» en La storiografia altomedievale: settimane di studio del centro italiano di studi sull'alto medioevo, XVII, 1016 aprile 1969. Spoleto, 1970, pp. 261-311.

Iglesias Ferreiro, A.: Historia de la traición. La traición regia en León y Castilla. Santiago de Compostela, 1971.

KAntorowicz, E. H.: Los dos cuerpos del rey. Un estudio de teología política medieval, Madrid, ed. 2012.

KING, P. D.: Derecho y sociedad en el reino visigodo. Madrid, ed. 1981.

Kolb, F.: Herrscherideologie in der Spätantike. Berlín, 2001.

López, R. S.: «Byzantine Law in the Seventh Century and its Reception by the Germans and the Arabs», Byzantion XVI, 1942-1943, pp. 445-461.

Maldonado Ramos, J.: "Algunos puntos precedentes y puntos oscuros de la rebelión de San Ermenegildo», en M. Bejarano, M. Montoro y D. SANDoval (dirs.): Los visigodos y su mundo. Jornadas internacionales. Ateneo de Madrid. Noviembre de 1990, Madrid, 1998, pp. 61-69.

McCormicк, M.: Eternal Victory, Triumphal Rulership in Late Antiquity, Byzantium and the Early Medieval West. Cambridge, 1986.

Molina Gómez, J. A.: «Las coronas de donación regia del tesoro de Guarrazar: la religiosidad en la monarquía visigoda y el uso de modelos bizantinos», Antigüedad y Cristianismo xxI, 2004, p. 459-472.

- «Las dos coronas de Paulo: elementos simbólicos de vestimenta y poder durante el reinado de Wamba», en Carmen Alfaro Giner, Jónatan Ortiz García y María Antón Peset (ed.): Tiarae, Diadems and headdresses in the Ancient Mediterranean Cultures. Symbolism and Technology, Valencia, 2014, pp. 263-271.

OrLANDIS, J.: «Algunas observaciones en torno a la tiranía de San Hermenegildo», Temis 2, 1957, pp. 67-75.

— «En torno a la noción visigoda de tiranía», AHDE, 29, 1959, pp. 5-43.

- (1962): El poder real y la sucesión al trono en la monarquía visigoda. Estudios visigodos III. Roma-Madrid.

ORLOWSKI, S. S.: «Fideles regis en el reino visigodo de Toledo: aproximaciones para su estudio desde las prácticas reciprocitarias», Miscelánea Medieval Murciana, XXXIV, 2010, pp. 83-91.

Paschoud, F. y Szidat, J. (eds.): Usurpationen in der Spätantike. Stuttgart, 1997. 
Patlagean, E.: «Byzance et le blason pénal du corps», en Du châtiment dans la cité. Supplices corporels et peine de mort dans le monde antique, Roma, 1982, pp. 405-427.

Petit, C.: «De negotiis causarum (II)», AHDE, 56, 1986, pp. 5-165.

- «Crimen y castigo en el reino visigodo de Toledo», en M. Bejarano, M. Montoro y D. Sandoval (dirs.): Los visigodos y su mundo. Jornadas internacionales. Ateneo de Madrid. Noviembre de 1990, Madrid, 1997, pp. 215-236.

RiEDE, P.: «Esel», en Biblelexicon, Deutsche Bibelgesellschaft, https://www. bibelwissenschaft.de/stichwort/17820/. (Consultado: 20/12/2015)

Rodríguez De LA PeÑA, M. A.: Los reyes sabios. Cultura y poder en la Antigüedad Tardía y la Alta Edad Media. Madrid, 2008.

SÁnchez Albornoz, C.: «La ordinatio principis en la España goda y postvisigoda», CHE 35, 1962, pp. 5-36.

Schramm, P. E.: «Brustbilder von Königen auf Siegelringen der Völkerwanderungszeit», en Herrschaftszeichen und Staatssymbolik, Schriften der MGA, vol. I, Stuttgart, 1954, pp. 213-237.

- «Mitherrschaft im himmel ein Topos des Herrscherkults in christlicher Einkleidung», en P. WirTh, (ed.): Polykronicon Festschrift für Franz Dölger,Heidelberg, 1966, pp. 480-485.

Straub, J. A.: Vom Herrscherideal in der Spätantike, Stuttgart, 1964.

- Regeneratio Imperii. Aufsätze über Roms Kaisertum und Reich im Spiegel der heidnischen und christlichen Publizistik, tomo II, «Des christlichen Kaisers 'secunda maiestas'. Tertullian und Konstantinische Wende», Darmstadt, 1986.

Stroheker, K. F.: Garmanentum und Spätantike, Zúrich, 1965.

TeIllet, S.: Des goths à la nation gothique. Les origines de l'idée de nation en Occident du $V^{e}$ au VII e siècle, París, 1984.

Thompson, E. A.: Los godos en España, Madrid, ed. 2007.

TORres López, M.: «El estado visigodo», AHDE 3, 1926, pp. 307-475.

Valverde Castro, M. ${ }^{a}$ R.: Ideología, simbolismo y ejercicio del poder real en la monarquía visigoda: un proceso de cambio. Salamanca, 2000.

Velázquez Soriano, I.: «Wamba y Paulo: Dos personalidades enfrentadas y una rebelión», Espacio, Tiempo y Forma, Serie II, Historia Antigua, t. II, pp. 213-222.

Vives Gatell, J., Marín Martínez, T. y Martínez Díez, G.: Concilios visigóticos e hispano-romanos, Madrid, 1963.

Zambrana Moral, P.: «Rasgos generales de la evolución histórica de la tipología de penas corporales», Revista de Estudios Históricos-Jurídicos, XXVII, 2005, pp. 197-229. 
ANEXO

\begin{tabular}{|c|c|}
\hline Argimundo (590) & Paulo (673) \\
\hline \begin{tabular}{l}
\multicolumn{1}{c}{ Reccaredo ergo orthodoxo } \\
quieta pace regnante domesticae \\
insidae praetenduntur. \\
Nam quidam ex cubiculo \\
eius, etiam provinciae dux \\
nomine Argimundus adversus \\
Reccaredum regem tyrannidem \\
assumere cupiens, ita tu, si posset, \\
eum regno privaret et vita. Sed \\
nefandi eius consilii detecta \\
machinatione comprehensus \\
et in vinculis ferreis redactus \\
habita discuccione socii eius \\
impiam machinationem confesii \\
condigna sunt ultione interfecti, \\
ipse autem Argimundus, qui \\
regnum assumere cupiebat, \\
primum verberibus interrogatus, \\
deinde turpiter decalvatus, post \\
haec dextra amputata exemplum \\
omnibus in Toletana urbe asino \\
sedens pompizando dedit et \\
docuit famulus dominis esse \\
superbos
\end{tabular} & $\begin{array}{l}\text { Etenim quarto fere ab urbe regia } \\
\text { miliario Paulus princeps tyrannidis } \\
\text { uel ceteri incentores seditionum } \\
\text { eius, decaluatis capitibus, } \\
\text { abrasis barbis pedibusque } \\
\text { nudatis, subsqualentibus ueste } \\
\text { uel habitu induti, camelorum } \\
\text { uehiculis imponontur. Rex ipse } \\
\text { perditionis praeibat in capite, omni } \\
\text { confusionis ignominia dignus et } \\
\text { picea ex coreis laurea coronatus. } \\
\text { Sequebatur deinde hunc regem } \\
\text { suum longa deductione ordo } \\
\text { suorum dispositus ministrorum, } \\
\text { eisdem omnes quibus relatum } \\
\text { est uehiculis insedentes } \\
\text { eisdemque inlusionibus acti, } \\
\text { hinc inde adstantibus populis, } \\
\text { urbem intrantes. Nec enim } \\
\text { ista sine dispensatione iusti } \\
\text { iudicii Dei eisdem accessisse } \\
\text { credendum est, scilicet tu alta } \\
\text { ac sublimia confusionis eorum } \\
\text { fastigia uehicolorum edoceret } \\
\text { sessio prae omnibus subiecta, } \\
\text { et qui ultra humanum morem } \\
\text { astu mentus excelsa petierant } \\
\text { excelsiores luerent conscensionis } \\
\text { suae iniuriam. Sint ergo haec } \\
\text { insequuturis reposita saeculis, } \\
\text { probis ad uotum, improbis ad } \\
\text { exemplum, fidelibus ad gaudium, } \\
\text { infidis ad tormentum, tu utraque } \\
\text { pars in contuitu quodam sese } \\
\text { lectionis huius inspiciens, et quae } \\
\text { rectis smitis graditur, prolapsionis } \\
\text { casus effugiat, et quae iam } \\
\text { cecidit, in horum se hic semper } \\
\text { proscriptionibus recognoscat. }\end{array}$ \\
\hline
\end{tabular}

